\title{
PEMBERDAYAAN IBU HAMIL TRIMESTER III DAN KELUARGA MENGGUNAKAN ENDORPHIN MASSAGE UNTUK MENGURANGI NYERI PINGGANG PADA KELAS IBU HAMIL
}

\section{THE THIRD TRIMESTER PREGNANT WOMEN AND FAMILY EMPOWERMENT USING ENDORPHIN MASSAGE TO REDUCE PAIN IN PREGNANT CLASS}

\author{
${ }^{1)}$ Nesi Novita, ${ }^{2)}$ Wita Asmalinda, ${ }^{3)}$ Desy Setiawati \\ ${ }^{1,2,3)}$ Program Study D3 Kebidanan Jurusan Kebidanan, Politeknik Kesehatan \\ Kemenkes Palembang, Indonesia \\ Jalan Jenderal Sudirman Kompleks RSMH Samping Mesjid Ass-Shofa \\ *Email: wita_asmalinda@yahoo.co.id
}

\begin{abstract}
ABSTRAK
Nyeri pinggang dapat menyebabkan timbulnya hiperventilasi sehingga kebutuhan oksigen meningkat, kenaikan tekanan darah, dan berkurangnya motilitas usus serta vesika urinaria. Penatalaksanaan nonfarmakologis untuk mengurangi nyeri persalinan dengan endorphin massage, yang merupakan sebuah terapi sentuhan ringan yang cukup penting diberikan pada wanita hamil, di waktu menjelang hingga saatnya melahirkan. Tujuan kegiatan ini adalah untuk pemberdayaan ibu hamil trimester III dan keluarga menggunakan endorphin massage untuk mengurangi nyeri pinggang dalam menghadapi persalinan pada kelas ibu hamil di Puskesmas Pakjo Palembang tahun 2019. Kegiatan pengabdian kepada masyarakat ini dilaksanakan selama 3 hari pada tanggal 23-25 September 2019. Tempat pelaksanaan kegiatan pengabdian masyarakat di Kelas Ibu Hamil Puskesmas Pakjo Palembang. Jumlah peserta kelas ibu hamil yang mengikuti kegiatan sebanyak 10 orang didamping keluarga. Hasil post-test menunjukkan jumlah ibu hamil dengan nyeri pinggang pada skala 0 adalah sebanyak 3 orang (30\%); skala 1-3 adalah sebanyak 6 orang (60\%); dan skala 4-6 adalah sebanyak 1 orang (10\%). Berdasarkan hasil kegiatan disimpulkan bahwa ada pengaruh pelatihan endorphin massage terhadap penurunan intensitas nyeri pinggang pada ibu hamil.
\end{abstract}

Kata kunci: Endorphin Massage; Kelas Ibu Hamil; Trimester III

\begin{abstract}
Low back pain can cause hyperventilation to increase oxygen demand, increase blood pressure, and decrease intestinal motility and vesica urine. Non-pharmacological management reduces labor pain with endorphin massage, which is a light touch therapy essential for pregnant women approaching delivery. The activity aims to empower third-trimester pregnant women and families to use endorphin massage to reduce low back pain in the face of childbirth in the pregnant mothers class at Pakjo Public Health Center in Palembang in 2019. This type of activity is based on research applied to community service activities. Community service activities were carried out for three days on September 23-25, 2019. The place of implementation of community service activities in the class of pregnant women, Pakjo Puskesmas Palembang. The number of pregnant class participants who took part in the activities was ten people accompanied by the family. The results of the post-test show the number of pregnant women with back pain scale 0; 1-3; and 4-6 are three people (30\%); 6 people (60\%); and one person (10\%), respectively. There is an effect of endorphin massage training on decreasing the intensity of low back pain in pregnancy.
\end{abstract}

Keywords: Endorphin Massage; Pregnant Class, Trimester III 


\section{PENDAHULUAN}

Persalinan merupakan hubungan saling mempengaruhi yang rumit antara dorongan psikologis dan fisiologis dalam diri wanita (Azizah, 2013; Varney, 2006). Tujuan dari persalinan adalah menjaga kelangsungan hidup dan memberikan derajat kesehatan yang tinggi bagi ibu dan bayinya melalui upaya yang terintegrasi dan lengkap, tetapi dengan intervensi yang seminimal mungkin agar prinsip keamanan dan kualitas pelayanan dapat terjaga (Astuti, \& Masruroh, 2013; Kuswandi, 2013). Proses persalinan identik dengan rasa nyeri yang akan dijalani. Secara fisiologis, nyeri terjadi ketika otototot rahim berkontraksi sebagai upaya membuka servik dan mendorong kepala bayi kearah panggul. Nyeri pada persalinan merupakan proses fisiologis yang disebabkan oleh proses dilatasi servik, hipoksia otot uterus saat kontraksi, iskemia korpus uteri dan peregangan segmen bawah rahim, dan kompresi saraf di servik (Azizah, Widyawati, \& Anggraini, 2013; Guyton, \& Hall, 2012; Kuswandi, 2013; Varney, 2006).

Nyeri persalinan dapat menimbulkan stress yang menyebabkan pelepasan hormon yang berlebihan seperti katekolamin dan steroid. Hormon ini dapat menyebabkan terjadinya ketegangan otot polos dan vasokonstriksi pembuluh darah. Hal ini dapat mengakibatkan penurunan kontraksi uterus, penurunan sirkulasi uteroplasenta, pengurangan aliran darah dan oksigen ke uterus, serta timbulnya iskemia uterus yang membuat impuls nyeri bertambah banyak (Kartikasari, \& Nurhayati, 2016; Guyton, \& Hall, 2012; Varney, 2006).

Nyeri persalinan juga dapat, menyebabkan timbulnya hiperventilasi sehingga kebutuhan oksigen meningkat, kenaikan tekanan darah, dan berkurangnya motilitas usus serta vesika urinaria. Keadaan ini akan merangsang peningkatan katekolamin yang dapat menyebabkan gangguan pada kekuatan kontraksi uterus sehingga terjadi inersia uteri yang dapat berakibat kematian ibu saat melahirkan (Llewllyn, 2001; Sherwood, 2014; Guyton, \& Hall, 2012)

Penatalaksanaan nonfarmakologis untuk mengurangi nyeri persalinan dengan endorphin massage. Endorphin Massage merupakan sebuah terapi sentuhan/ pijatan ringan yang cukup penting diberikan pada wanita hamil, di waktu menjelang hingga saatnya melahirkan (Aryani, Masrul, \& Evareny, 2015; Haghighi, Masoumi, \& Kazem, 2016; Sulistyawati, 2017). Selama ini endorphin sudah dikenal sebagai zat yang banyak manfaatnya. Beberapa diantaranya adalah mengatur produksi hormon pertumbuhan dan seks, mengendalikan rasa nyeri serta sakit yang menetap, mengendalikan perasaan stres, serta meningkatkan sistem kekebalan tubuh. Munculnya endorphin dalam tubuh bisa dipicu melalui berbagai kegiatan, seperti pernapasan yang dalam dan relaksasi, serta meditasi (Kuswandi, 2013; Sulistyawati, 2017). Tujuan kegiatan ini adalah untuk pemberdayaan ibu hamil trimester III dan keluarga mengunakan endorphin massage untuk mengurangi nyeri pinggang dalam menghadapi persalinan pada kelas ibu hamil di Puskesmas Pakjo Palembang Tahun 2019

\section{METODE}

Kegiatan pengabdian kepada masyarakat ini merupakan kegiatan berbasis riset tentang Endorphin massage yang diaplikasikan pada kelas ibu hamil. Kegiatan ini dilaksanakan melalui beberapa tahapan antara lain: tahap persiapan, pelaksanaan, monitoring dan evaluasi, pembuatan laporan, dan penyerahan laporan. Kegiatan 
menggunakan metode ceramah disertai pemberian pelatihan/ demonstrasi (peragaan) teknik massage endorphin. Tempat pelaksanaan kegiatan adalah di kelas ibu hamil Puskesmas Pakjo Palembang. Waktu pelaksanaan selama 3 hari pada tanggal 2325 September 2019. Khalayak sasaran adalah peserta kelas ibu hamil beserta suaminya sebanyak 10 pasang. Sarana dan prasarana untuk kegiatan pelatihan adalah : ruang belajar yang cukup luas, meja, kursi, LCD, infokus dan sound system, serta peralatan pelatihan endorphin massage seperti banner, ATK, booklet/ leaflet, matras, musik, aroma terapi, bantal/ guling/ balok, dan selimut. Dress code mengunakan pakaian olahraga/ senam untuk semua peserta pelatihan, tim pelaksana (dosen dan mahasiswa), dan juga pihak Puskesmas Pakjo Palembang.

Sebelum acara dimulai, peserta diminta untuk mengisi absensi. Kegiatan pelatihan endorphin massage di kelas ibu hamil diawali dengan acara pembukaan pada pukul 09.00 WIB oleh Pimpinan Puskesmas Pakjo, Dilanjutkan dengan pretest pengukuran intensitas nyeri mengunakan Visual Analogue Scale (VAS) (Potter \& Perry, 2006). Sesi selanjutnya adalah penyampaian materi tentang endorphin massage oleh ibu Nesi Novita, dan dilanjutkan dengan peragaan/ demontrasi tehnik endorphin massage oleh ibu Wita Asmalinda. Selanjutnya suami/ keluarga peserta dipersilakan untuk mempraktikkan tehnik endorphin massage. Sesi selanjutnya adalah tanya jawab tentang materi yang sudah disampaikan dan praktik mandiri bagi semua peserta pelatihan.

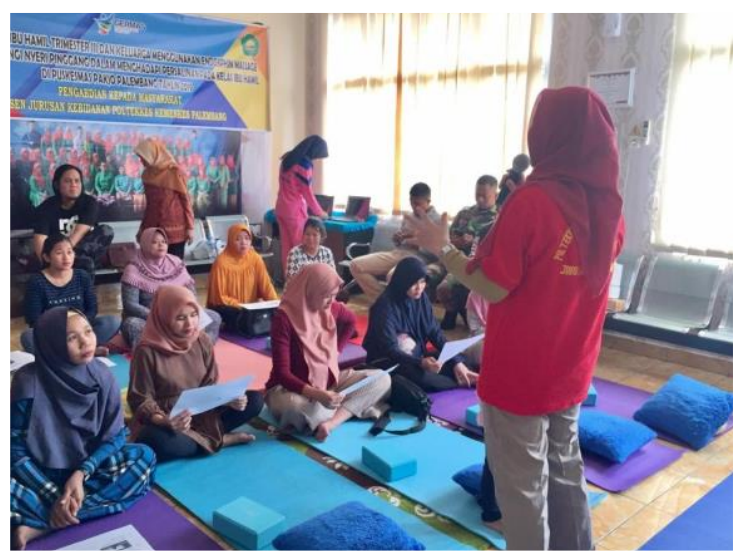

Gambar 1: Penyampaian Materi

(Sumber : Dokumentasi Pengmas, 2019)

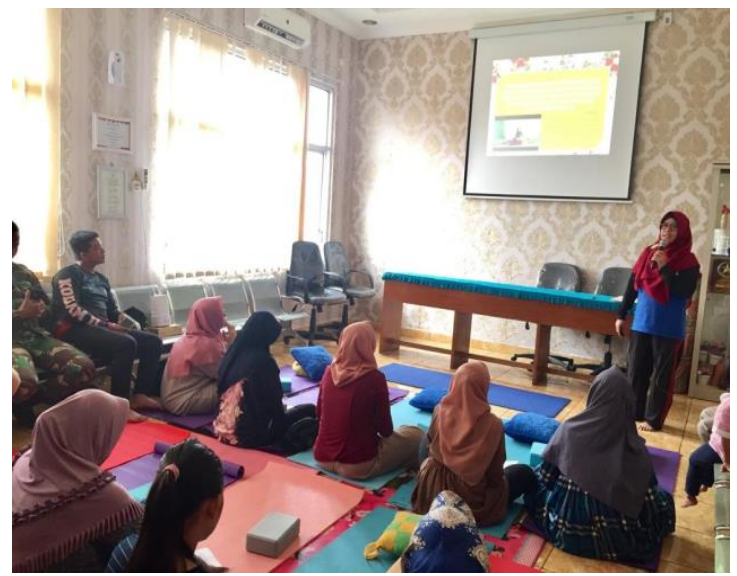

Gambar 2: Penyampaian Materi

(Sumber : Dokumentasi Pengmas, 2019)

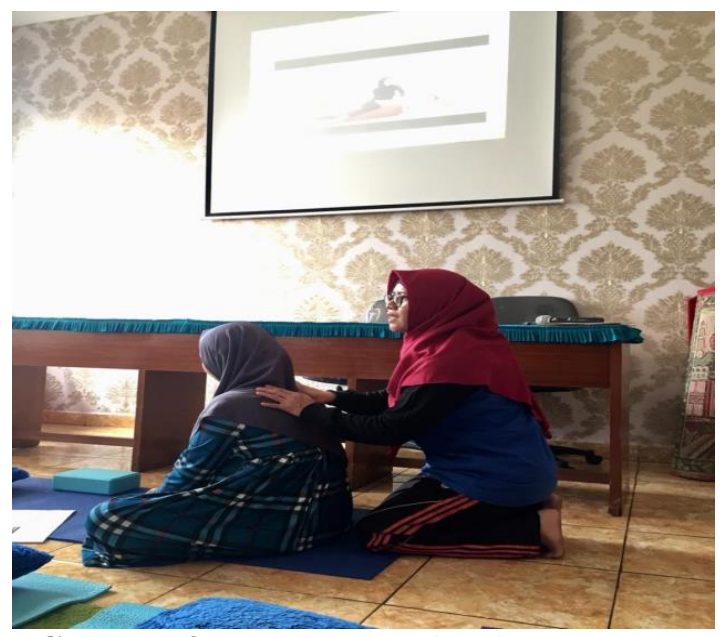

Gambar 3: Peragaan Endorphin Massage

(Sumber : Dokumentasi Pengmas, 2019) 


\section{HASIL DAN PEMBAHASAN}

Pengabdian kepada masyarakat adalah suatu kegiatan institusi yang dilaksanakan oleh dosen sebagai salah satu bentuk dharma atau tugas pokok perguruan tinggi, disamping dharma Pendidikan dan dharma penelitian sebagaimana tertuang dalam Tri Dharma Perguruan Tinggi. Pengabdian kepada masyarakat dapat dilaksanakan dalam bentuk pendidikan kesehatan, pelatihan, pelayanan/ penerapan hasil penelitian atau dalam bentuk lain sesuai perkembangan zaman. Dengan diadakannya kegiatan pengabdiaan kepada masyarakat diharapkan adanya kesatuan emisi dan rasa saling membutuhkan antara perguruan tinggi dan masyarakat. Kegiatan pengabdian kepada masyarakat yang dilakukan oleh kelompok dosen dan mahasiswa ini adalah pelatihan di kelas ibu hamil Puskesmas Pakjo Palembang.

Pelaksanaan pelatihan endorphin massage ini dilaksanakan secara partisipatif. Ibu-ibu hamil diposisikan tidak hanya sebagai penerima materi namun sebagai warga belajar. Dalam praktiknya setelah menyampaikan materi, narasumber mendemonstrasikan prosedur endorphin massage yaitu dengan instruksi sebagai berikut: pertama Anda dapat melakukan endorphin massage ini dengan duduk ataupun berbaring. Usahakan suami Anda berada di samping Anda. Lakukan terapi ini dengan duduk ataupun berbaring dengan nyaman. Tarik nafas secara perlahan kemudian keluarkan dengan sangat lembut sambil pejamkan mata Anda. Mintalah pada suami Anda untuk mengelus permukaan kulit pada lengan Anda dengan lembut menggunakan jari tangan suami Anda. Mulailah pada lengan atas kemudian turun hingga pada lengan bawah Anda. Lakukan hal ini dengan perlahan serta lembut, dan ganti pada tangan lainnya setelah beberapa menit. Anda dapat melakukan hal ini pada bagian tubuh yang lainnya seperti: bahu, punggung, leher, dan juga paha.

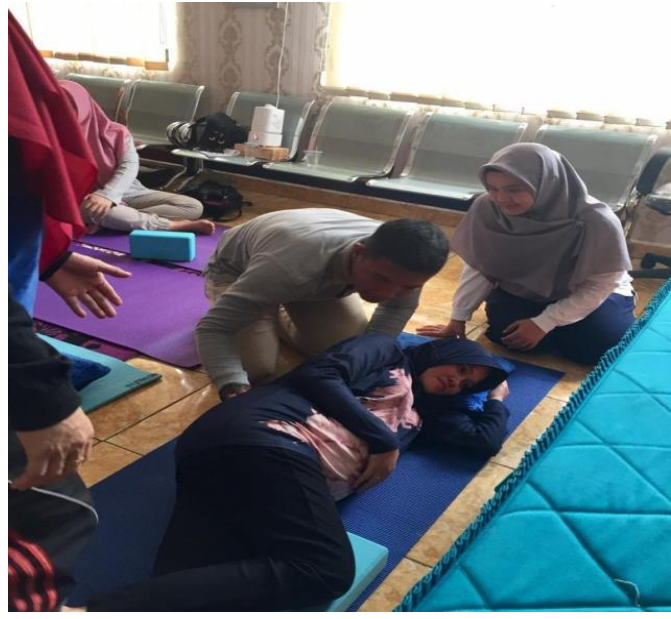

Gambar 4: Peragaan oleh peserta

(Sumber : Dokumentasi Pengmas, 2019)

Pelaksanaan Kelas Ibu Hamil Puskemas Pakjo Palembang bertempat di ruang pertemuan/ ruang rapat yang berada di lantai dua gedung puskesmas. Kegiatan ini dimulai dengan kegiatan persiapan, dimana dosen sebagai pelaksana kegiatan berkoordinasi dengan Pimpinan Puskesmas Pakjo Palembang dan Bidan Koordinator Puskesmas untuk menentukan waktu dan tempat pelaksanaan, selanjutnya mempersiapkan tempat pelaksanaan kelas ibu hamil, sarana dan prasarana pelatihan Endorphin Massage, dan mendata jumlah ibu hamil yang akan mengikuti kegiatan.

\section{Karakteristik Peserta Pelatihan Endorphin Massage}

Tabel 1. Karakteristik Umur Peserta

\begin{tabular}{lcc}
\hline Umur (tahun) & $\mathbf{n}$ & $\mathbf{\%}$ \\
\hline $21-30$ & 7 & 70 \\
$31-40$ & 3 & 30 \\
\hline Total & $\mathbf{1 0}$ & $\mathbf{1 0 0}$ \\
\hline
\end{tabular}

Tabel 1 menunjukkkan bahwa dari 10 peserta kelas ibu hamil Puskesmas Pakjo Palembang didapatkan kisaran umur 21-30 tahun adalah sebanyak 7 orang (70\%) sedangkan peserta yang berusia 31-40 tahun sebanyak 3 orang (30\%). 
Nesi Novita, Wita Asmalinda, Desy Setiawati

Pemberdayaan Ibu Hamil Trimester III dan Keluarga Menggunakan Endorphin Massage Untuk

Mengurangi Nyeri Pinggang Pada Kelas Ibu Hamil

\begin{tabular}{lcclcc}
\multicolumn{2}{c}{$\begin{array}{c}\text { Tabel 2. Karakteristik Tingkat Pendidikan } \\
\text { Peserta Kelas Ibu Hamil }\end{array}$} & \multicolumn{3}{c}{$\begin{array}{l}\text { Tabel 5. Distribusi Nyeri Pinggang Peserta } \\
\text { Berdasarkan Hasil Pretes Pemeriksaan VAS }\end{array}$} \\
\hline Jenis Pendidikan & $\mathbf{n}$ & $\mathbf{\%}$ & Hasil $\boldsymbol{V A S}$ & $\mathbf{N}$ & $\mathbf{\%}$ \\
\hline SD & 0 & 0 & Skala 0 & 0 & 0 \\
SMP & 1 & 10 & Skala 1-3 & 2 & 20 \\
SMA & 4 & 40 & Skala 4-6 & 7 & 70 \\
D4 & 1 & 10 & Skala 7-9 & 1 & 10 \\
S1 & 4 & 40 & Skala 10 & 0 & 0 \\
\hline Total & $\mathbf{1 0}$ & $\mathbf{1 0 0}$ & Total & $\mathbf{1 0}$ & $\mathbf{1 0 0}$ \\
\hline
\end{tabular}

Tabel 2 menunjukkkan bahwa dari 10 peserta kelas ibu hamil didapatkan tingkat pendidikan peserta yang terbanyak adalah SMA 4 orang $(40 \%)$ dan S1 adalah sebanyak 4 orang (40\%).

Tabel 3. Status Gravida Peserta Kelas Ibu

\begin{tabular}{lrr} 
& Hamil & \\
\hline Status Gravida & $\mathbf{n}$ & $\%$ \\
\hline Primigravida & 6 & 60 \\
Multigravida & 4 & 40 \\
\hline Total & $\mathbf{1 0}$ & $\mathbf{1 0 0}$ \\
\hline
\end{tabular}

Tabel 5 menunjukkkan bahwa dari 10 peserta kelas ibu hamil yang mengikuti pretes pemeriksaan skala intensitas nyeri menggunakan VAS Visual Analogue Scale Skala berupa garis lurus yang panjangnya biasanya $10 \mathrm{~cm}$ (atau $100 \mathrm{~mm}$ ) dengan penggambaran verbal pada masing-masing ujungnya seperti angka 0 (tanpa nyeri) sampai angka 10 (nyeri hebat). Skala ini memberikan kebebasan pada klien untuk mengidentifikasi keparahan nyeri dan lebih sensitif karena mengidentifikasi setiap titik

Tabel 3 menunjukkkan bahwa dari 10 peserta kelas ibu hamil didapatkan status gravida peserta yang terbanyak adalah primigravida (kehamilan pertama) yaitu sebanyak 6 orang $(60 \%)$ sedangkan peserta status multigravida (kehamilan lebih dari 1) adalah sebanyak 4 orang (40\%).

Tabel 4. Usia Kehamilan Peserta Kelas Ibu

\begin{tabular}{lcr}
\multicolumn{3}{c}{ Hamil } \\
\hline Usia kehamilan & $\mathbf{n}$ & $\mathbf{\%}$ \\
\hline Trimester I & 0 & 0 \\
Trimester II & 6 & 60 \\
Trimester III & 4 & 40 \\
\hline Total & $\mathbf{1 0}$ & $\mathbf{1 0 0}$ \\
\hline
\end{tabular}

Tabel 4 menunjukkkan bahwa dari 10 peserta kelas ibu hamil didapatkan usia kehamilan peserta yang terbanyak adalah pada trimester II yaitu sebanyak 6 orang (60 $\%$ ) sedangkan usia kehamilan peserta trimester III adalah sebanyak 4 orang (40\%). pada rangkaian daripada dipaksa memilih satu kata atau satu angka.

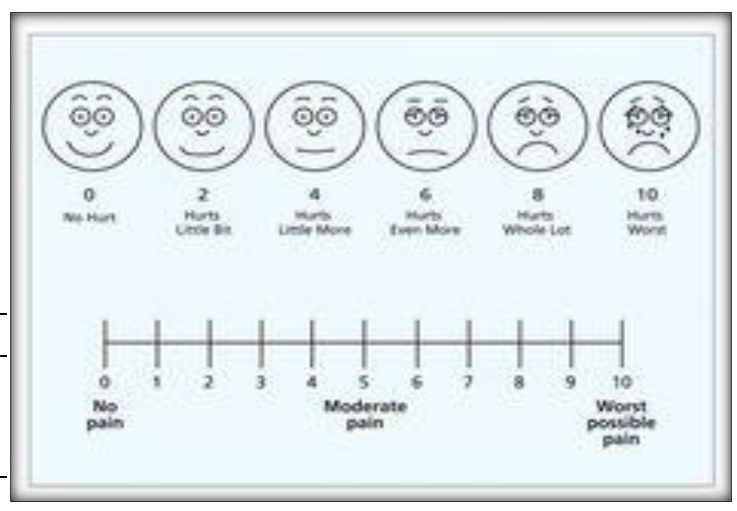

Gambar 5: Skala VAS

(Sumber : Potter, \& Perry, 2006)

Hasil pretes menunjukkan ibu hamil dengan skala VAS 1-3 adalah sebanyak 2 orang (20\%); skala 4-6 adalah sebanyak 7 orang (70\%); sedangkan skala 7-9 adalah sebanyak 1 orang (10\%). 
Tabel 6. Distribusi Nyeri Pinggang Peserta Berdasarkan Hasil Post-test Pemeriksaan

\begin{tabular}{lcc}
\multicolumn{3}{c}{$V A S$} \\
\hline Hasil $\boldsymbol{V A S}$ & $\mathbf{N}$ & $\mathbf{\%}$ \\
\hline Skala 0 & 3 & 20 \\
Skala 1-3 & 6 & 70 \\
Skala 4-6 & 1 & 10 \\
Skala 7-9 & 0 & 0 \\
Skala 10 & 0 & 0 \\
\hline Total & $\mathbf{1 0}$ & $\mathbf{1 0 0}$ \\
\hline
\end{tabular}

Tabel 6 menunjukkan bahwa dari 10 peserta kelas ibu hamil yang mengikuti post-test pemeriksaan skala nyeri mengunakan VAS didapatkan ibu hamil dengan skala 0 (tidak nyeri) adalah sebanyak 3 orang (30\%), skala 1-3 (rasa nyeri seperti gatal atau tersetrum atau nyut-nyutan atau melilit atau terpukul atau perih atau mules) adalah sebanyak 6 orang (60\%), dan dengan skala 4-6 (seperti ham atau kaku atau tertekan atau sulit bergerak atau terbakar atau ditusuk-tusuk) adalah sebanyak 1 orang (10\%).

Tabel 7. Distribusi Tingkat Kemahiran Peserta Berdasarkan Hasil Pengamatan Peragaan Endorphin Massage

\begin{tabular}{lcl}
\hline Hasil Peragaan & N & \% \\
\hline Kurang Mahir & 0 & 0 \\
Cukup Mahir & 3 & 30 \\
Mahir & 6 & 60 \\
Sangat mahir & 1 & 10 \\
\hline Total & $\mathbf{1 0}$ & $\mathbf{1 0 0}$ \\
\hline
\end{tabular}

Tabel 7 menunjukkkan bahwa dari 10 peserta kelas ibu hamil yang dapat memperagakan tehnik endorphin massage dengan benar dan sesuai Standar Operasional Prosedur Endorphin massage dengan kriteria sangat mahir adalah sebanyak 1 orang (10\%), yang mahir adalah sebayak 6 orang (60\%), dan yang cukup mahir adalah sebanyak 3 orang (30\%).

Berdasarkan hasil pengabdian masyarakat ini menunjukkan terjadinya penurunan skala nyeri pinggang peserta pelatihan. Hasil ini sejalan dengan hasil penelitian Kartikasari \& Nurhayati (2016).Terjadi penurunan yang bermakna terhadap intensitas nyeri punggung pada ibu hamil yang diberikan Endorphin massage. Endorphin massage merupakan teknik sentuhan serta pemijatan ringan, yang dapat menormalkan denyut jantung dan tekanan darah, serta meningkatkan kondisi rileks dalam tubuh ibu hamil dengan memicu perasaan nyaman melalui permukaan kulit. Pijatan akan merangsang tubuh untuk melepaskan senyawa endorphin yang merupakan pereda rasa sakit dan dapat menciptakan perasaan nyaman (Kuswandi, 2013). Endorphin mempunyai manfaat antara lain: mengatur produksi hormon pertumbuhan dan seks, mengendalikan rasa nyeri serta sakit yang menetap, mengendalikan perasaan stres, serta meningkatkan sistem kekebalan tubuh. Produksi endorphin dalam tubuh dipicu melalui berbagai kegiatan, seperti pernapasan yang dalam dan relaksasi, serta meditasi (Kuswandi, 2013).

$$
\text { Endorphin massage dalam }
$$

kehamilan dan persalinan sebaiknya terapi ini dilakukan oleh ibu beserta suami pada saat usia kehamilan di atas 36 minggu, hal ini disebabkan oleh hormon oksitosin yang telah keluar dapat merangsang terjadinya kontraksi. Terapi endorphin massage sangat mendukung terapi relaksasi yang cukup dalam serta dapat membantu dalam membentuk ikatan ibu, suami juga bayi anda yang masih di dalam kandungan ibu. Endorphin ini merupakan hormon alami yang dapat diproduksi pada tubuh ibu hamil, dengan begitu endorphin ini ialah penghilang rasa nyeri yang paling baik. Endorphin ini juga diproduksi dengan alami saat melakukan kegiatan seperti meditasi, melakukan teknik pernafasan yang dalam, mengkonsumsi makanan yang cukup pedas, dan juga melalui teknik acupunture treatments. Meski terapi sentuhan yang ringan ini dapat dilakukan oleh siapa pun yang mampu mendampingi wanita yang 
Nesi Novita, Wita Asmalinda, Desy Setiawati

Pemberdayaan Ibu Hamil Trimester III dan Keluarga Menggunakan Endorphin Massage Untuk

Mengurangi Nyeri Pinggang Pada Kelas Ibu Hamil

sedang hamil, namun ada baiknya terapi ini dilakukan bersama pasangan atau suami. Beberapa ahli mengatakan terapi ini akan semakin meningkat jika terdapat hubungan yang erat antara istri, suami beserta bayi yang hendak di lahirkannya.

\section{SIMPULAN}

Kegiatan pengabdian kepada masyarakat oleh kelompok dosen dan dibantu oleh mahasiswa Jurusan Kebidanan Prodi DIII Kebidanan yang dilaksanakan di Kelas Ibu Hamil Puskesmas Pakjo Palembang berjalan dengan lancar. Kegiatan pengabdian kepada masyarakat ini mampu menghasilkan luaran-luaran yang diharapkan dan peserta pelatihan memperoleh pengetahuan keterampilan tentang endorphin massage yang sangat bermanfaat untuk mengurangi nyeri pinggang selama kehamilannya.

Kegiatan pengabdian kepada masyarakat ini berdampak cukup besar kepada masyarakat sekitar. Karena kegiatan seperti ini dapat dirasakan langsung manfaatnya, disarankan agar kegiatan pelatihan ini dapat diteruskan di kelas ibu hamil Puskesmas Pakjo Palembang. agar lebih banyak ibu hamil di wilayah kerja Puskesmas Pakjo Palembang dapat merasakan manfaat dari kelas ibu hamil.

\section{DAFTAR PUSTAKA}

Potter, \& Perry, AG. (2006). Buku Ajar Fundamental Keperawatan: Konsep, Proses, dan Praktik, 4th ed. EGC. Jakarta.

Astuti, A.P., \& Masruroh (2013). Perbedaan Lama Kala I Fase Aktif pada Ibu Bersalin yang Dilakukan dan yang Tidak Dilakukan Pijat Endorphin di RB Margo Waluyo Surakarta". Jurnal Kebidanan. 5(1), 30-36. http://dx.doi.org/10.35872/jurkeb.v5i $\underline{2.109}$
Aprilia, Y., \& Ritchmond, B. (2011). Gentle Birth. Jakarta: Gramedia Widiasarana Indonesia

Aryani, Y., Masrul, \& Evareny, L. (2015). Pengaruh Masase pada Punggung terhadap Intensitas Nyeri Kala I Fase Laten Persalinan Normal melalui Peningkatan Kadar Endorphin).Jurnal Kesehatan Andalas. 4(1),70-7. https://doi.org/10.25077/jka.v4i1.19 $\underline{3}$

Azizah, IN., Widyawati, MN., \& Anggraini NN. (2013). Pengaruh Endorphin Massage terhadap Intensitas Nyeri Kala I Persalinan Normal Ibu Primipara di BPS S dan B Demak. Jurnal Kebidanan Universitas Muhammadiyah Semarang. 2(1), 906.

https://doi.org/10.26714/jk.2.1.2013. $\% 25 \mathrm{p}$

CSA., Hadi, \& Widyawati, MN. (2015). Aromatherapy Massage As An Alternative in Reducing Cortisol Level and Enhancing Breastmilk Production on Primiparous Postpartum Women in Semarang. 4th Asian Academic Society International Conference (AASIC), 381-388.

Departemen Kesehatan. (2007). Asuhan Persalinan Normal. Jakarta. Depkes RI.

Dewi, MM., Sukini, T., Ath Thaariq, NA., \& Hidayati, NM. (2017). Effectiveness of Endorphins Massage and Ice Packs to Relieve The First Stage of Labor Pain Among The pegnant Women in Candimulyo Health Center Indonesia. 2 nd International Conference on Applied Science and Health Research for Better Society: Developing Science and Technology to Improve. ICASH-A015, 1-6. 
Nesi Novita, Wita Asmalinda, Desy Setiawati Pemberdayaan Ibu Hamil Trimester III dan Keluarga Menggunakan Endorphin Massage Untuk Mengurangi Nyeri Pinggang Pada Kelas Ibu Hamil

East, CE., Begg, L., Henshall, NE., Marchant P., \& Wallace K. et al (2009). Local Cooling for Relieving Pain from Perineal Trauma Sustained during Childbirth. Cochrane Database Syst Rev. (5):CD006304. https://doi.org/10.1002/14651858.cd 006304.pub3

Eshkevari, L, Trout, KK., \& Damore J. (2013). Management of Postpartum Pain. Journal of Midwifery and Women's Health.58, 622-31. https://doi.org/10.1111/jmwh.12129

Gorji, H., Nesami, B., Ayyasi, Ghafari, \& Yazdani. (2014). Comparison of Ice Packs Application and Relaxation Therapy in Pain Reduction during Chest Tube Removal Following Cardiac Surgery. North American Journal of Medical Sciences. 6(1), 19-24.

https://dx.doi.org/10.4103\%2F19472714.125857

Haghighi, NB., Masoumi, SZ., \& Kazemi, F. (2016). Effect of Massage Therapy on Duration of Labour : A Randomized Controlled Trial. Journal of Clinical and Diagnostic Research. 10(4), 5-12. https://doi.org/10.7860/jcdr/2016/17 447.7688

Bottom of Form Hosseini, E., Asadi, N., \& Zareei, F. (2013). Effect of Massage Therapy on Labour Progress and Plasma Levels of Cortisol in the Active Stage of First Labor. Zahedan Journal of Research in Medical Sciences. 15(9), 35-38.

Judha, M., Sudarti, \& Fauziah, A. (2012). Teori Pengukuran Nyeri dan Nyeri Persalinan. Yogyakarta: Nuha Medika

Kartikasari, RI., \& Nurhayati, A. (2016). Pengaruh Endorphin massage
Terhadap Penurunan Intensitas Nyeri Punggung Ibu Hamil. Rakernas Aipkema. Temu Ilmiah Hasil Penelitian dan Pengabdian Masyarakat.

Kusumaningsih, R., Hasan, M., \& Kusuma, IF. (2015). Relationship between Obesity and Degree Pain in Knee Osteoarthritis Patients at Bina Sehat Hospital Jember. e-Jurnal Pustaka Kesehatan. 3(2), 253-6.

Kuswandi, L. (2013). Hypnobirthing A Gentle Way to Give Birth. Jakarta: Pustaka Bunda.

Lilyana, T. (2019) Terapi Endorphin Massage. Available on: http://www.academia. edu/12498 411/. Accessed 22 Maret 2019

Llewellyn, D. (2001). Dasar-dasar Obstetri dan Ginekologi.Edisi 6. Jakarta: Hipokrates.

Sherwood. (2012). Fisiologi Manusia; dari Sel ke Sistem. Edisi 8. Jakarta: EGC.

Sulistyawiati, H. (2017). Pengaruh Endorphin Massage Terhadan Penurunan Intensitas Nyeri Punggung Ibu Hamil (Studi di BPM Lia Astari Kec. Mojoagung Kab. Jombang)

Taghinejad, H., Delpisheh, A., \& Suhrabi, Z. (2016). Comparison between Massage and Music Therapy to Relieves the Severity of Labor Pain. Women's Health. 6(3), 377-81.

Tournarie, \& Yonnea. (2007). Review Complementary and Alternative Approaches to Pain Relief During Labor. Evidence Based Complementary and Alternative Medicine.4. Available: http://dx.doi.org/10/1093/ecam/nem 012. [PubMed]. 
Uliyah \& Hidayat. (2006). Keterampilan Dasar Praktik Klinik Kebidanan. Jakarta. Salemba Medika

Varney, H. (2006). Buku Ajar Asuhan Kebidanan.Edisi 4, Vol. 1 Jakarta: EGC. 